lower costal margin at that time, and very fortunately segregation of the urine revealed pus coming from the right kidney. Exploratory operation revealed a large perinephritic abscess which compressed the right suprarenal against the lower surface of the liver on that side. Evacuation and drainage of that caused prompt return of his power. I followed the case for about six months after that, when he returned to Kansas, and took up his occupation. The case was distinctly myasthenic in type, and at that time was reported as a case of Addison's disease from a perinephritic abscess.

Dr. William A. Jones, Minneapolis: In the literature on myasthenia gravis I found nothing relating to speech defects, particularly stammering. I have seen but few cases of what I believed were true myasthenia gravis, and the two or three I have in mind at the present time have manifested no marked change, and are still living fairly comfortable lives. The tumor in the case I reported was about the size of a large Damask plum, and naturally occupied a considerable space in the mediastinal region.

\section{EXPERIMENTAL STUDIES OF INJECTION OF THE GASSERIAN GANGLION}

$$
\begin{gathered}
\text { CONTROLLED BY FLUOROSCOPY * } \\
\text { LEWIS J. POLLOCK, M.D. } \\
\text { HOLLIS E. POTTER, M.D. } \\
\begin{array}{c}
\text { CHICAGo } \\
\text { ChD }
\end{array}
\end{gathered}
$$

A perusal of the contemporaneous literature leads to the conclusion that gasserian ganglion operations and intraneural or intraganglionic injections of alcohol are the procedures of selection for the treatment of trifacial neuralgia.

The technical difficulties of operations on the gasserian ganglion or its sensory root and the relatively high mortality attending such operations, except in the hands of a very few surgeons, made welcome a procedure which offered at least alleviation without danger, disagreeable sequelae or great difficulty.

The injection of pain deadening and nerve destroying substances into the trifacial nerve dates back to 1874, when Bartholow reported successes with the injection of chloroform. Successful results with the injection of osmic acid were recorded through a period of years following Billroth and Neuber in 1884, by Eulenberg, Shapiro, Bennet, Murphy, Wright and others.

It was not until Schlösser reported the results of his experiments in 1903 that persistent efforts were inspired for the development of a technic for successful alcoholization of the fifth nerve. About the same time further impetus was given by the work of Ostwald, Levy and Baudoin. The technic of the latter two was adopted by Patrick, Hecht, Sicard, Harris and others. The development of the technic and the reports of its successful employment by these workers has placed this procedure permanently among the methods employed for the effective relief of trifacial neuralgia.

It is not within the scope of this paper, which deals with a technical problem, to describe the details of the development of methods of injection and their results.

Suffice it to say that in the hands of operators who have had wide experience and who have developed consummate skill, all these methods are uncertain. As

* Read before the Section on Nervous and Mental Diseases at the Sixty-Seventh Annual Session of the American Medical Association, Detroit, June, 1916.
Patrick" says, "It requires little experience or reflection to realize that no one can uniformly touch with a needle a given point 4 to $5 \mathrm{~cm}$. ( 2 inches) below the surface."

The uncertainty of prevailing methods led us to pursue some experimental work on which this paper is based. We are concerned with reaching the gasserian ganglion through the foramen ovale. Part of the experiments deal with a route which Harris uses in his technic. He, with Patrick and others, employs with little modification the course adopted by Levy and Baudoin. The needle is inserted in the sigmoid notch from 1.5 to $2.5 \mathrm{~cm}$. anterior to the anterior root of the zygoma or from a point immediately in front of the preglenoid tubercle, to one a centimeter farther forward. The needle is directed somewhat backward and slightly forward, and at $4 \mathrm{~cm}$. should reach the nerve. The needle arrives at the foramen ovale after having passed through the skin, subcutaneous tissue, the zygomatic insertion of the masseter, posterior portion of the

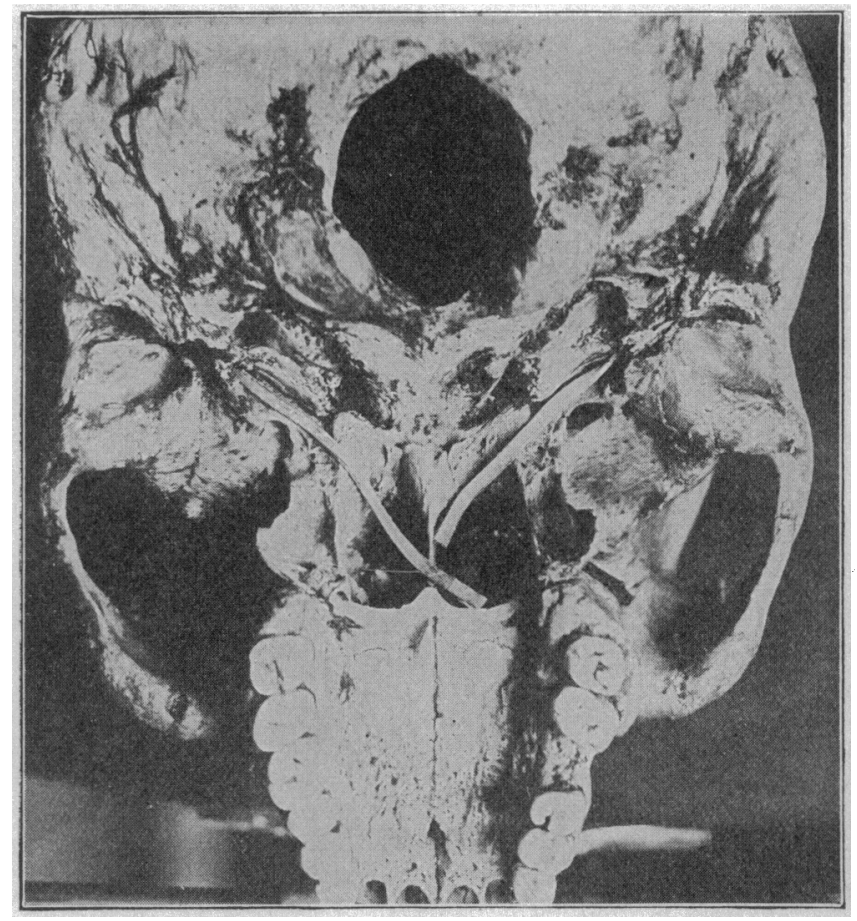

Fig. 1.-Lead strips in the groove of the eustachian tube, showing the foramen ovale immediately external and anterior to it.

temporal tendon, superior border of the externai pyterygoid muscle and lastly in the front of the temporo-maxillary articulation. Patrick ${ }^{2}$ has called attention to the fact that:

A really valuable landmark is the external pterygoid plate. The foramen ovale, at least in the vast majority of cases, is directly back of this and at about the same depth. Hence I aim to strike this plate close to its posterior edge and then work backward until the needle slips by it. Then I have every reason to believe that the point of the needle is just in front of the nerve and at about the proper depth.

Patrick gives a very valuable guide to be used in determining the approximate depth of the foramen from the surface. Analysis of his measurements in

1. Patrick, Hugh T.: The Treatment of Trifacial Neuralgia by Means of Deep Injections of Alcohol, THE Journal A. M. A., Nov. 9, 1907 , p. 1567.

2. Patrick, Hugh T.: The Technic and Results of Deep Injections of Alcohol for Trifacial Neuralgia, The Journal. A. M. A., Jan. 20, 1912 , p. 155 . 
eighty cases indicates the following: When the interzygomatic diameter is 5 inches, the nerve will be found at 4 to $4.25 \mathrm{~cm}$. When the interzygomatic is $51 / 2$ inches, the nerve is apt to be at over $4.5 \mathrm{~cm}$.

If one follows these various details of procedure, the needle may be inserted to a place in very close proximity to the foramen, and we are concerned with making this proximity as great as possible.

A study of the anatomy of the parts about the foramen ovale shows that along the line of the sphenopetrosal fissure the edges of the adjacent sphenoid and petrous-temporal bones are beveled "so as to form a groove which extends from the root of the inner pterygoid internally, to the inner side of the base of the alar spine externally . . . in the groove is lodged the cartilaginous part of the eustachian tube.

Between the root of the external pterygoid plate and the alar spine there are two foramina which lie directly in front of the sulcus of the eustachian tube. Of these the larger and anterior is the foramen ovale." (Cunningham.)

A view of a sagittal section of the skull at the plane of the foramen ovale shows that it is directly in front of, above and internal to the eustachian tube. A study of both sides of fourteen skulls showed that however the groove for the eustachian tube varied in its course, the bone separating the sulcus from the foramen varied in thickness but from 1 to $3 \mathrm{~mm}$.

It follows that to successfully introduce a needle into the foramen ovale it is necessary only to visualize the eustachian tube and to establish certain angles and lines which would by means of the fluoroscope enable one to determine when the point of the needle is in front, above and external to the eustachian tube at a proper depth.

The visualization of the direction and approximate location of the eustachian tube is easily accomplished by the introduction of a eustachian catheter with the assistance of a nasopharyngoscope (so that one is certain of having entered the ostium), and by inserting through the catheter a bougie made of fuse lead or one made of flexible spirally wound gold wire. This, when it is inserted to a depth of about 1 inch beyond the end of the catheter, is about at the beginning of the isthmus of the tube at its entrance into the osseous canal. The course and position of the tube can now readily seen by means of the fluoroscope (Fig. 2 ).

The rays should enter the head at the opposite occipitoparietal protuberance at an angle of 120 degrees to a coronal section, and at an angle of 45 degrees to a sagittal section of the head. Under these conditions, a needle introduced at the sigmoid notch and taking a direction approximately at an angle of 20 degrees to the sagittal suture and 130 degrees to the coronal section would be directed toward the foramen ovale and be projected on the screen as traveling downward toward the eustachian tube, at an angle of 90 degrees from the point of entrance.

If the needle is introduced in this direction to a depth determined by computation from the intertubercular diameter, and does not cross the shadow thrown by the eustachian bougie, it is at its proper depth.

If the rays now be shifted so that they enter in the direction of the needle, the butt of the needle should appear above the eustachian tube, determining its proper height. This leaves undetermined the anteroposterior location of the foramen. The bony structure seen through the inferior border of the zygomatic surface of the great wing of the sphenoid throws a shadow running anteroposteriorly and upward and when visible, the foramen ovale may be found somewhere along its course.

An approximate formula may be formed. If under the above conditions a needle be introduced to a point above the eustachian tube, and to a depth not crossing
,

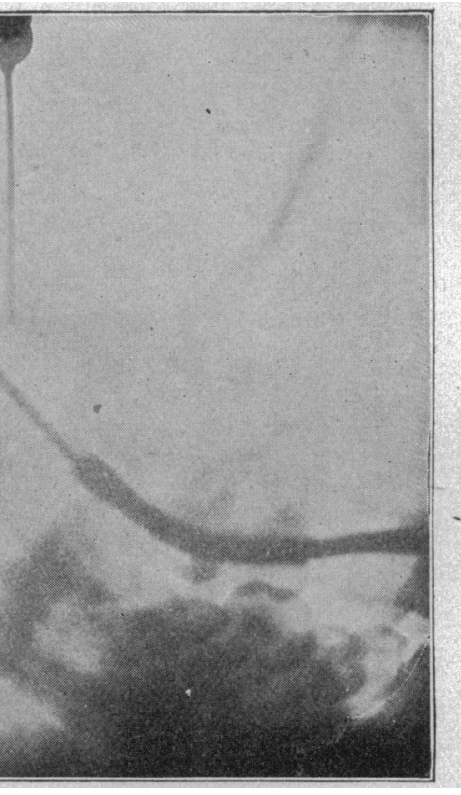

Fig. 2.-Needle in foramen ovale and eustachian bougie in position. The needle can be seen entering the foramen on the linear shadow cast by the structure through the inferior border of the great wing of we are dealing with live subj it, it can be caused to enter the foramen ovale by directing it at points along the described line from before backward. When this line is not visible, the needle may be directed from 0.5 to $1 \mathrm{~cm}$. above the shadow of the eustachian bougie.

A large number of factors entering into the optical physics of the formation of the shadow of the eustachian bougie make the distance between the shadows of the eustachian bougie and foramen ovale vary to such a degree that the actual distance cannot be computed.

On cadaver heads this method offers such assistance that a needle can be successfully introduced into the ganglion on each attempt. When, however, thects, a new factor is introduced which for the time precludes the possibility of the employment of this method. We attempted this method in three cases and found that the secondary rays developed in the tissues, principally the brain, diffusing the shadow of the slender needle to such an extent that proper methods of diaphragming must first be developed that will eliminate these rays before the fluoroscopic projection of the eistachian tube may be cmployed as a means of accurately locating the foramen ovale.

Failing in this direction, we began to study another route.

Härtel $^{3}$ has given us a route which has made the approach through the foramen ovale more practical and useful. To Grinker," who first made Härtel's method known to American readers, we are indebted for some of the following description. The needle is

3. Härtel, F.: Arch. f. klin. Chir., c, No. 1.

3. Hartel, F.: Arch. f. klin. Chir., c, No. 1. Trigeminus by the Injection of Alcohol into the Gasserian Ganglion, The Jaurnal A. M. A., May 3, 1913, p. 1354. 
introduced through the cheek opposite the alveolar process of the second upper molar tooth. It is guided by means of a finger in the mouth so as to pass between the anterior ramus of the lower jaw and tuberosity of the superior maxilla. "Causing the needle to sweep around the buccinator muscle, the operator pushes it onward between this muscle and the masseter, coronoid process of the lower maxilla and the temporal muscle externally, into the zygomatic fossa. Continuing in the direction upward, backward and slightly inward, the needle now reaches the broad under surface of the great wing of the sphenoid, having pierced the external pterygoid muscle, which fills the zygomatic fossa."

According to Härtel, the needle points to the pupil of the eye of the same side and on lateral view the needle points to the articular eminence on the zygoma. The needle engages the foramen ovale at a depth of about $6 \mathrm{~cm}$. from the point of entrance.

$\mathrm{Maes}^{5}$ has found that the foramen was more accessible from a point behind the last molar tooth of the lower jaw than from the point given by Härtel. From a study of forty skulls we found that projecting a pin through the foramen ovale hugging the anterior border of the petrous portion of the temporal bone, the point of entrance would fall in most instances at a point between the second and third molars of the upper jaw.

The depth to which the needle should be introduced may be more accurately estimated by using the data we have derived from an examination of both sides of forty skulls. The distance from the point of entrance of the needle to the preglenoid tubercle, or the alveolar tubercular measurement, was greater than the distance from the point of entrance to the foramen ovale or alveolar foraminal measurement in all but two instances. Of these, one was an anomalous skull, and the other, one in which the intertubercular measurement exceeded $51 / 2$ inches. In all other skulls it was found that the alveolar foraminal was less than the alveolar tubercular measurement by from 0.1 to $0.9 \mathrm{~cm}$. Eighty per cent. of the cases showed a difference of less than $0.6 \mathrm{~cm}$., 50 per cent. less than $0.4 \mathrm{~cm}$. Of the cases showing a difference of over 0.6, many occurred where the intertubercular diameter was less than $5 \mathrm{~cm}$., and some where the alveolar tubercular measurement exceeded $5.5 \mathrm{~cm}$. The depth of the foramen from the zygoma did not bear a constant relation to the alveolar foraminal measurement, except in that where the foramen was deeply situated the alveolar foraminal measurement was often inclined to be greater than usual.

The anterior border of the petrous portion of the temporal bone, when the head is viewed exactly laterally through the fluoroscope, throws a shadow easily seen in living subjects. This shadow forms a line

5. Maes, Urban: Surg., Gynec. and Obst., 1915, xxi, 449. which is a direct projection of the shadow cast by a needle entering a point between the second and third molars of the upper jaw. If, therefore, a needle be introduced here and pushed, according to Härtel's directions, to a depth computed by our measurements, it will be approximately at the foramen ovale. If now the needle be directed so that a projection of the shadow would follow the shadow of the anterior border of the petrous portion of the temporal bone, or 1 or $2 \mathrm{~mm}$. below it, the anteroposterior and superior planes of the foramen ovale will be accurately located. The internal and external planes of the foramen ovale cannot be located by the fluoroscope, and one is guided by Härtel's direction to point at the pupil of the same eye and by the pterygoid bone. The superior inferior plane may be further determined, if necessary, by employing a shadow of an opaque eustachian bougie, when the needle should be above it, and here the secondary rays do not interfere with the visibility of the shadow of the needle.

In our experiments, employing both sides of the fourteen heads, no difficulty was experienced in introlucing the needle into the foramen ovale on each attempt. It might be said that the introduction of a needle into a given point of a cadaver which cannot bleed, suffer pain or experience injuries of various important structures, is quite a different matter from accomplishing the same result in the living subject.

We have had only one opportunity of using this method on a living subject. Here the lower and middle branches of the ganglion were easily reached and injected, with immediate relief of pain and good analgesia.

In conclusion we may say that employing the shadow cast by the anterior border of the petrous portion of the temporal bone, on a fluoroscope, as a line of orientation injection of the gasserian ganglion by Härtel's method is made more certain.

25 East Washington Street-122 South Michigan Avenue.

\section{ABSTRACT OF DISCUSSION}

Dr. Hugh T. Patrick, Chicago: It remains to be seen whether Dr. Pollock's method will prove to be a practical one to be used in the majority of these cases. The method of Härtel, under proper guidance, perhaps according to the method which Dr. Pollock has devised, may prove to be an entirely practical and practicable procedure; but I must say that under the rules which Härtel himself originated, I never had the courage to attempt to inject the gasserian ganglion.

I may exaggerate the dangers a great deal but $\mathbf{I}$ do not really want to demonstrate to myself that it is a dangerous procedure. The operation has, of course, been done successfully a number of times, and I hope under the scientific guidance of Dr. Pollock we may be able to do this accurately and without danger. And this is a consummation devoutly to be wished. Injection of the ganglion by the Harris method is disappointing to me. I have tried it a number of times; occasionally the needle goes through the foramen ovale and 
reaches the gasserian ganglion or its vicinity with a facility comparable to putting one's hand in one's pocket. And the next time the needle does not find the foramen at all.

Dr. Julius Grinker, Chicago: While in Berlin in 1902-1903 I saw Härtel demonstrate his method, which was new then. I also saw the cases as he demonstrated them before the Berlin Surgical Society. There were five patients, each one having been afflicted with a very formidable sort of tic douloureux and each one having received a number of peripheral nerve injections without benefit. Relief came promptly after Härtel's injections. The first injections were made, not to relieve neuralgia, but to anesthetize the face for operation. For this purpose Härtel uses small doses of novocain introduced into the gasserian ganglion, which permit operation on any part of the face without a general anesthetic. It was the ease with which he succeeded in anesthetizing the face that led him to adopt the injection of alcohol directly into the ganglion as a means of giving relief for trigeminal neuralgia. My own impression of the method is that it is not more difficult than injection by the Boudouin-Levy method with which Dr. Patrick made us acquainted. When first shown to me, I thought it a rather formidable procedure - to take a needle of such large caliber and bore a hole in the patient's face. Nevertheless we tried it and succeeded in giving relief to many unfortunate sufferers. Härtel uses a very fine needle, so fine, indeed, that it matters little whether you introduce it twenty times or only once. It does no damage if you follow his directions. Nevertheless, I believe a simplified method would be a great advantage. Personally I do not so much fear the difficulty of getting into the ganglion, as the consequences of having entered the ganglion, namely, the corneal ulceration. As a successful gasserectomy done by the surgeon is in many instances followed by ulceration of the cornea, so do we get a similar result after successful injection of the ganglion. And it is this apprehension which has really prevented me from repeating the injection more than twice. In short, I fear the aftereffects of a successful injection much more than the

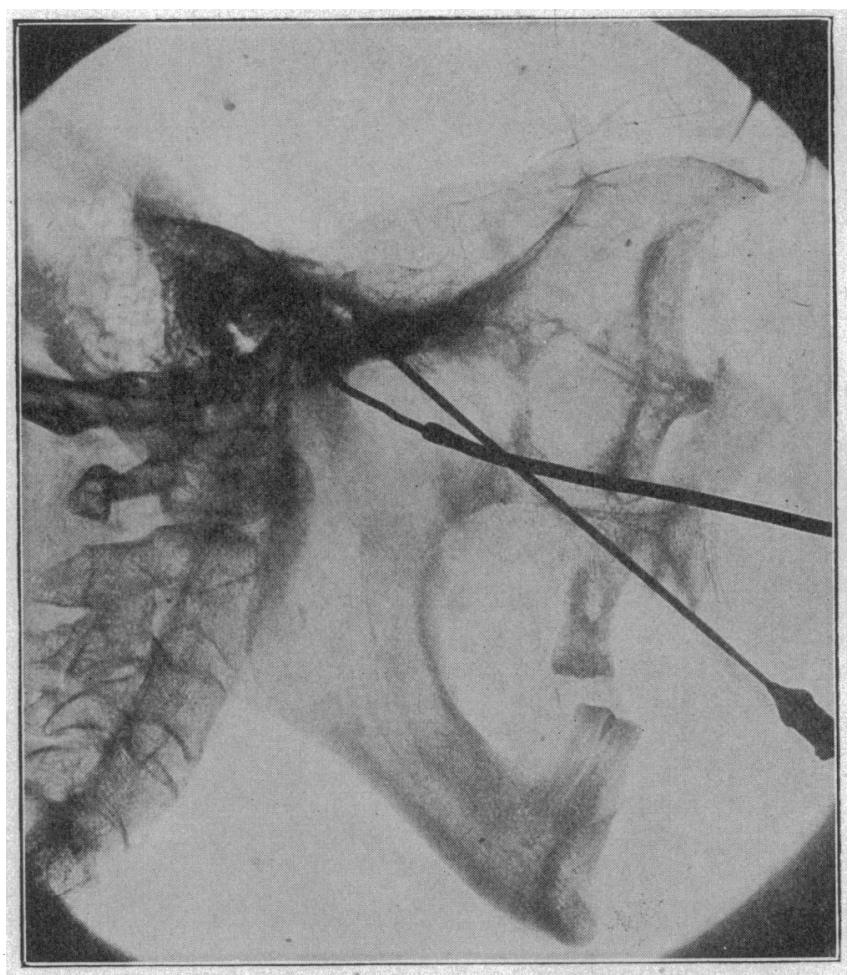

Iig. 4.- Needle in the foramen ovale, the eustachian bougie in place to indicate the proper height. again. Another objection to the fine needle is that a little bit of blood is liable to cause it to become occluded, particularly if you have squeezed a few drops of alcohol through the end of the needle. Alcohol coagulates blood very readily, and it is most distressing sometimes to find that you are in the correct position, but that the needle is occluded.

In getting into the gland I have had the experience related by Dr. Patrick. When I heard Dr. Harris describe his method it seemed good, so I practiced on a cadaver and found no difficulty in entering the foramen ovale from the side according to the Harris method, also no difficulty in entering the foramen ovale from the front according to the Härtel method. But I noticed that many times when I went into the foramen of a living. subject this did not mean that I had got into the ganglion by any means, but that the end of the needle was under some dense tissue, and this tissue prevented me from injecting the ganglion with alcohol.

The best ganglion injection I ever made was an accidental one. I was trying to inject the third branch of the nerve according to the Levy-Boudouin method. I introduced the needle to the point where I thought the exit of the third branch ought to be and injected about 1 c.c. of a 90 per cent. solution of alcohol. The patient immediately went into collapse, became unconscious, had paralysis on that side of the face, and I thought she was going to die on the table. She was over 80 years old. The facial paralysis was the most complete I ever saw, but this did not bother her a bit; we had a beautiful anesthesia of the three branches of the fifth nerve and she was highly pleased and delighted with the results. Last winter I had one of the most intractable cases that I have ever encountered. I am sure that $I$ entered his foramen ovale according to the Härtel method on two different occasions and injected alcohol. On one occasion I got facial paralysis and nystagmus, anesthesia of all the branches of the fifth, and temporary anesthesia of the cornea, and yet, with the exception of the partial anesthesia of the cornea, the pain still continued.

DR. ERNEST SACHS, St. difficulty of getting into the foramen.

Dr. M. A. Bliss, St. Louis: I have felt that the injection of alcohol was a more or less temporary measure. The cells of the ganglion are much more resistant to alcohol than are the fibers of the trunk, according to the observations I have seen quoted. I would like to ask whether in any successful injection of the gasserian ganglion the anesthesia and the relief from pain is reasonably permanent.

Dr. Charles R. Ball, St. Paul: For about eight years I have been making these injections by the Boudouin-Levy method which Dr. Patrick first brought to this country. Injection of the ganglion is no trivial procedure. The procedure is to be entered on with a proper sense of appreciation of the danger connected with it. In the first place we must have the right sort of a needle. I sent to Berlin and procured Härtel's injection outfit; since then I have been using the Härtel needle in all my injections. It has the disadvantage that after you start your direction, the needle is so fine that you cannot change it; therefore if you do not enter the foramen you have to withdraw the needle and start over
Louis: Dr. Ball is frank enough to tell us of the untoward accidents. I should certainly hesitate to undertake any procedure when I had such complications. I judge that what happened in Dr. Ball's case was that when the alcohol was put into the cavum meckeli it went where the cerebrospinal fluid goes; when you open the cavum meckeli you always get discharge of cerebrospinal fluid. I have had no experience with injection of the ganglion; I would not think of doing it or trying it. Gasserectomy, when carefully done, is not the dangerous operation that it is generally supposed to be. About a month ago Dr. Harvey Cushing reported about 150 gasserectomies without a single death, no complications, except one or two corneal ulcers which healed, and no blindness. It would seem to me that results of that sort are far better than doing an operation which is absolutely in the dark and very dangerous.

Dr. George Morris Dorrance, Philadelphia: In cases of operation on the face, we inject the ganglion with novocain to obtain the required anesthesia. We injected 300 cadavers, making 600 injections. In some cases we went under the 
ganglion and that made us fail; in others, over the ganglion, sometimes hitting only a part of the ganglion. I usually get it the first or second time and it comes easy after doing a few. You should, of course, inject novocain before the alcohol. If you get complications, you do not inject the alcohol but withdraw the needle and make a second puncture. If the neuralgia is confined to the third division, you do not necessarily inject the ganglion, but the third division only. However, it is not difficult to inject the ganglion. We do have recurrences, but when the operation is done right along, the procedure is not so difficult as has been intimated by Dr. Sachs. Sometimes we do find a difficult case; sometimes the material will not diffuse through the ganglion easily. Be sure to use the novocain first. It saves getting into these terrible complications.

Dr. Lewis John Pollock, Chicago: It was not my intention either to provoke or to enter into a general discussion as to the merits of alcoholization of the component portions of the nerve or the ganglion itself. I had felt, contrary to the impression of Dr. Dorrance, that injection of the ganglion was difficult, irrespective of any procedure known at the present time; and that if a method could be devised which would make it more certain and less liable to be followed by any untoward results, we would be doing some service. The dangerous zone in doing the Härtel injection lies not anteriorly, but posteriorly, inferiorly and internally. If the needle is kept so that it enters not more than one or two millimeters below the shadow of the anterior border of the petrous portion of the temporal bone, it cannot go either too far back or too low down. Therefore, it will strike either the external plate of the pterygoid or the large wing of the sphenoid and you can do no damage to the structures here. As to Dr. Grinker's apprehension concerning the production of corneal ulcers, one should, of course, mention this complication under the discussion of advantages and indications and contraindications of injection of alcohol, and other methods of surgical treatment of trifacial neuralgia as well. In reply to Dr. Bliss, I would state that the ganglionic as well as the intraneural injections are only temporary. But in experimental work done by Byrnes it has been found that the sensory cells of the ganglion itself do degenerate and that this practically puts the nerve out of commission, more so than injections into the nerve itself. Of course, it is not necessary to inject the ganglion by this method; you do not have to push the needle in all the way; you can inject the lower branch alone, and that is the branch which is difficult to inject. The middle branch is easily injected. And it is not necessary to include all the ganglion in the injection if one proceeds carefully; if one is guided by proper measurements he will be able to separate the injection of the third branch from that of the first. I was very glad to hear Dr. Dorrance bring out the roint that one can inject the third branch alone.

Refer'ing to Dr. Sach's remarks, from a review of the literatu e as well as from personal observations, I feel certain that these untoward accidents do not result in permanent damage and, further, that they occur but very seldom, and exceeringly seldom as compared with the general results obtained by all general surgeons collectively in operations on the gisserian ganglion or its sensory root.
A FURTHER NOTE ON THE DIAGNOSTIC VALUE OF RETROBULBAR NEURITIS IN EXPANDING LESIONS OF THE FRONTAL LOBES

WITH A REPORT OF THIS SYNDROME IN A CASE OF ANEURYSM OF THE RIGHT INTERNAL CAROTID ARTERY *

FOSTER KENNEDY, M.D., F.R.S.(EIN.)

Neurologist to Bellevue and New York Hospitals

NEW YORK

Difficulty in the diagnosis of cerebral lesions varies directly with the degree of physiologic latency possessed by the affected brain area.

Again, even when tissue subserving active function becomes irritated or destroyed by disease, our difficulty in decision as to the part involved depends largely on the degree of objectivity in the phenomena produced.

The vertigo accompanying cysticercus of the fourth ventricle eludes the descriptive powers of the majority of patients, nor are the uncinate fits associated with irritative processes in the hippocampal gyri more easily portrayed: in consequence of the difficulty in describing concretely $\mathrm{such}$ subjective states, occurrences of the most precise character are apt to be misinterpreted by even alert observers. In the recognition of disease affecting the frontal lobes there is ample illustration of the truth of these general propositions. These gyri are not only highly latent, but such exigtious symptomatology as has been ascribed to them consists mainly of certain illdefined abnormalities of mentality and conduct.

It is, therefore, proposed in this short communication again ${ }^{1}$ to draw attention to a syndrome referable to the inferior frontal areas, a clinical picture also which is capable of such objective investigation as tc facilitate decisively the diagnosis of pressure-producing lesions of these parts.

The sign of which I wish to speak is the occurrence of a true retrobulbar neuritis, with the formation of a central scotoma and primary optic atrophy on the side of the lesion together (if pressure be sufficiently great) with ipsolateral anosmia and papilledema in the opposite eye. The mode of production of this situation may be illustrated by the case of a woman, aged 53 , kindly referred to me by Dr. John Shannon in

* Read before the Section on Nervous and Mental Diseases at the Sixty-Seventh Annual Session of the American Medical Association, Detroit, June, 1916.

1. Kennedy, Foster: Retrobulbar Neuritis as an Exact Diagnostic Sign of Certain Tumors and Abscesses of the Frontal Lobes, Am. Jour. Med. Sc., September, 1911. 